\section{INFLUENCIA DE LA FOTOGRAFÍA EN LA LITERATURA ESPAÑOLA Y LATINOAMERICANA}

\author{
Antonio Ansón \\ Departamento de Filología Francesa \\ Universidad de Zaragoza \\ Ciudad Universitaria, $s / n$ \\ 50009 Zaragoza \\ aanson@unizar.es
}

\begin{abstract}
Research on the influence of photography in Spanish literature from the late nineteenth century onwards. The study focuses on works of fiction by Spanish and Latin American writers.
\end{abstract}

KEY WORDS: Photography; literature; Spanish; Latin American; interdisciplinary studies.

Mucho se ha escrito sobre la influencia recíproca entre cine y literatura. Mucho menos, irrelevante si la comparamos con la anterior, sobre la presencia que la fotografía ha tenido en la literatura desde su nacimiento a finales del siglo XIX'. Ningún otro medio de expresión, sin embargo, ha tenido la presencia que tiene la imagen fotográfica no sólo en la literatura, sino en el arte en general y también en la vida cotidiana. La fotografía del interior del cuerpo humano desempeña un papel clave en La montaña mágica (1924) de Thomas Mann, al igual que diferentes manifestaciones fotográficas en la monumental En busca del tiempo perdido (1913-1927) de Proust. El amante (1984) de Marguerite Duras fue concebido como un álbum de familia comentado, al que se terminó por suprimir las ilustraciones ofreciendo al lector sólo los textos. Y si el estudio sobre las relaciones entre fotografía y literatura es limitado, el interés por la presencia de la fotografía en la literatura en español es inexistente. $Y$ no obstante tiene una gran relevancia, como se trata de mostrar a continuación.

Miguel de Unamuno es uno de los primeros ${ }^{2}$ en recurrir a la técnica fotográfica de la sobreimpresión para ilustrar en En torno al casticismo (1895) su idea de "abstracción". Unamuno describe el modo en que diferentes rostros de un mismo árbol genealógico ${ }^{3}$ pueden ser impresionados unos sobre otros para obtener una imagen única que reúna la síntesis de todos ellos subrayando los caracteres comunes ${ }^{4}$. La des-

\section{INFLUENCE OF PHOTOGRAPHY IN THE SPANISH AND LATIN AMERICAN LITERATURE}

RESUMEN: Investigación sobre la influencia de la fotografia en la literatura en español desde finales del siglo XIX hasta nuestros días. El estudio se centra en obras de narrativa de autores españoles y latinoamericanos.

PALABRAS CLAVE: Fotografía; literatura; España; Latinoamérica; estudios interdisciplinares.

cripción que el filósofo hace de este recurso corresponde a una exposición múltiple sobre una única placa como paso previo a su positivado, dedicando tiempos parciales a cada uno de los rostros, dispuestos en un ángulo similar de modo que sus facciones se confundan en el retrato final. No deja de sorprender, en cualquier caso, que para hablar de la abstracción, Unamuno eche mano de una forma de representar tan poco abstracta, al menos de momento. Mediante la impresión múltiple y la reserva de algunas partes sobre el positivo, se consiguen los fotomontajes propios de la experimentación de los años 20 y 30 .

Ansúrez, el personaje principal de La vuelta al mundo en la "Numancia" (1906) de Benito Pérez Galdós, tras una serie de peripecias en busca de su hija en América y de vuelta a España, conoce durante su viaje en la goleta Numancia al maquinista Fenelón, de origen francés, quien se atribuye una dudosa fama de conquistador ofreciendo como prueba indiscutible una serie de retratos de mujeres a los que va atribuyendo la sorprendente historia de fotografías que en este capítulo se detalla. Se trata de una fantasía sobre retratos de bellas mujeres vendidos en el puerto por muy poco dinero $0^{5}$. Fenelon no hace otra cosa que construir una fantasía, en este caso amorosa, sobre la argumentación que se pretende irrevocable de los supuestos retratos de sus amantes. La fotografía, en este caso, actúa como testigo de cargo está al servicio de una ficción erótica. 
El cuento de Baroja "Medium", incluido en su primer libro de relatos, publicado en 1900 con el título de Vidas sombrías, recoge un tema recurrente en la literatura de finales del XIX: los fantasmas y la fotografía". "Medium" está escrito en los años en que Baroja estudia medicina y comienza a ejercer en Cestona y Madrid. Su cuento refleja ese mismo interés por partida doble, como médico y hombre de letras que ha viajado por Europa. La fotografía desempeña en el relato de Baroja el papel de prueba concluyente y objetivable de la existencia, primero intuida y luego descubierta en el revelado y posterior positivo de las placas, de un fantasma sólo visible gracias a la intervención de la cámara. El espíritu positivista conseguirá demostrar cientificamente que existen otras realidades que conviven con las naturales y visibles más allá de la consciencia, y no por ello menos reales. Freud y la psicología reconcilian ciencia y arte al servir como detonador de surrealismo, la corriente literaria que marcará indiscutiblemente el pensamiento y la estética de todo el siglo XX.

Este argumento por el cual la cámara ve cosas que pasan inadvertidas para el ojo se repetirá en otras ocasiones a lo largo de la literatura fotográfica ${ }^{7}$. Los cuentos de Horacio Quiroga "El espectro", incluido en El desierto (1924), "La cámara oscura" en Los desterrados (1926), así como "El vampiro" perteneciente a su libro El más allá (1935), abordan, aunque con matices muy distintos, la vida dentro y fuera de las imágenes. Se trata, una vez más, de una realidad fantasmagórica. Pero si en los relatos precedentes el objetivo de la cámara es captar y probar la existencia de un espíritu, dejando claramente delimitada la frontera que separa el mundo real (de los vivos) y el mundo real (de la imágenes), en el caso de "El espectro", en primer lugar, el autor guatemalteco plantea la posibilidad que entre las dos realidades se abra una puerta a través de la cual los personajes circulan, con mayor o menor fortuna, de aquí para allá y viceversa.

"Hay leyes naturales -escribe en 'El espectro'- principios físicos que nos enseñan cuán fría magia es esa de los espectros fotográficos danzando en la pantalla, remedando hasta en los más mínimos detalles una vida que se perdió" (Quiroga, 1995, 118-119). Este relato, que pone en escena un triángulo amoroso unidos fatalmente por el cine, o mejor habría que decir, por la pantalla cinematográfica, plantea una comunicación entre vida real y vida virtual, en donde ficción y realidad se debaten en un ir y venir de un lado a otro del espejo. En el relato de Quiroga, los personajes quedan a merced del estreno de una película cuyo título lo dice todo, Más allá de lo que se ve, y que sólo su estreno podrá redimirlos de su cautiverio virtual.

Más enigmático y complejo es "El vampiro", donde la especulación sobre las posibilidades de construir una realidad virtual al margen de la realidad física pone en marcha un universo imaginario lleno de posibilidades. El resultado es una suerte de imagen holográfica de una mujer traslúcida con la que conviven los protagonistas de la narración. "Mi vida a los rayos de sol -escribe el narrador- ha sido una alucinación, y yo he visto un fantasma creado para desempeñar ese papel. Mi existencia real se ha deslizado, ha estado contenida como en un cripta, bajo la alcoba amorosa y el dosel de plafonniers lívidos, donde en compañía de otro hombre hemos rendido culto a los dibujos en losange de muro, que ostentaban por todo corazón es espectro de una mujer" (Quiroga, 1995, 61). Esta existencia se salda con un resultado trágico para todos los personajes que participan del experimento. "El vampiro" de Horacio Quiroga anuncia, por sus manifiestas similitudes, el universo holográfico que Bioy Casares pondrá en escena más tarde en La invención de Morel (1940). En esta novela corta del argentino Bioy Casares se aborda un asunto de moda desde que Platón describiera su célebre caverna y hoy puestos en práctica en sitios como Second Life: los límites improbables entre realidad y ficción. La invención de Morel plantea la existencia de una vida posible y por completo artificial al margen de la cotidiana.

El retrato postmortem ${ }^{8}$, una práctica fotográfica que hasta hace bien poco pretendia salvar para la eternidad de la imagen y para el recuerdo al que acababa de morir, constituye la base argumental de relatos como "La cámara oscura" de Quiroga o "Locos van y vienen" de María Teresa León. El fotógrafo narrador de "La cámara oscura" tiene que revivir el rostro al revelar el retrato del cadáver de Malaquías Sotelo, que emerge sumergido en la cubeta de revelado. Su rostro vuelve de la muerte igual que el gitano Melquiades vuelve de la muerte y del olvido en Cien años de soledad (1967) de García Márquez "porque no pudo soportar la soledad" para refugiarse en Macondo e instalar un laboratorio de daguerrotipia.

María Teresa León en su cuento "Locos van y vienen", publicado por primera vez en Buenos Aires en 1942 junto 
a otros relatos bajo el título Morirás lejos, y recogido más tarde en la selección Una estrella roja (1979), tiene también como uno de sus temas principales el retrato mortuorio, una práctica que nació a la par que la fotografía. "Locos van y vienen" forma parte, si bien el relato se sitúa espacialmente en Argentina, de la historia oscura y fiera de una España que Cristina Garcia Rodero ${ }^{9}$ ha sabido retratar con pulcritud notarial. La historia nos remite a entierros sórdidos con curánganos y mercaderes de misas y rosarios para comprar una parcela de cielo, cuyo plano extiende el mosén como un vendedor ambulante. La niña muerta espera con sus alitas de cartón envueltas en papel dorado a que su madre consiga por tres misas un lugar en el paraíso junto a la azucena en una nube rosa, al abrigo, con sol y más niños para jugar, cuando irrumpe el fotógrafo y el negocio celestial se va al traste por la oferta inmejorable de un retrato de todos los hermanos junto al angelito a cinco pesos por cabeza "para tenerlos presente ante mis ojos hasta el día de la muerte" (León, 1979, 129), dice la madre. Cuarenta pesos por la eternidad, y todos felices al fin redimidos del olvido y de la muerte que es el olvido.

No es el único ejemplo en el que María Teresa León se interesa y se ocupa de la fotografía. En otros relatos de ese mismo libro, como el delicioso "El perfume de mi madre era el heliotropo" y "Zapatos para el viento"10, aparecen más fotos de familias, de novias y de niños. Su novela Juego limpio (1959) está plagada de referencias a la fotografía, desempeñando en algunos casos un papel decisivo en el desarrollo argumental de la historia. Mucho más relevante aún es la presencia de fotógrafos y fotografías en su libro, a mi juicio el menos valioso y sin embargo más reeditado y conocido, Memoria de la melancolía (1975). Además de numerosos comentarios a fotos, se habla de los reporteros André Friedmann, más conocido como Robert Capa ${ }^{11}$, autor de esa imagen, convertida ya en icono emblemático, del miliciano caído en combate, y Gerda Taro ${ }^{12}$, que murió de forma accidental al ser golpeada por un carro de combate mientras iba subida en el estribo de un camión durante la retirada de Brunete en julio de 1937, recordados ambos por María Teresa León como los "huéspedes más queridos de la Alianza de Intelectuales".

De todos los escritores en español, Ramón Gómez de la Serna es con toda seguridad aquel que más páginas ha dedicado a la fotografía, ya no sólo como uno de sus temas predilectos vinculados a la actualidad social, sino como pretexto para crear imágenes y personajes sorprendentes. En "Cuadros y fotografías" (El rastro, 1914), Gómez de la Serna parece ofrecernos una nueva versión de las Coplas de Manrique en ese cafarnaúm existencial que se amontona en los tenderetes del rastro. La infancia en las fotografías de niños, que son un retrato para siempre de cada uno de los niños que guardamos dentro, la vanidad y el poder que encierran los retratos de las actrices de ópera y los artistas de circo, los retratos de los reyes y de los grandes hombres, las estériles orlas de licenciado con toda su "abrumadora mediocridad" se amontonan para recordarnos que la corriente de nuestras vidas, con su ambición y su vanidad, terminarán indefectiblemente entre los cachivaches del rastro, y en el mejor de los casos aspirar a esa "vivienda entre las nubes" que es limbo de todos los retratados, petrificados por el "monstruo de un solo ojo", descrito por Gómez de la Serna en "Los juguetes en las fotografías" (Libro nuevo, 1920).

En "Mujer sin ojos en mi fotografía", que forma parte de Las muertas (1910) pone en escena el asunto fascinante de los álbumes de familia. La mejor novela no puede competir con cualquiera de nuestros álbumes, asegura Günter Grass en Tambor de hojalata (1959). El suyo encierra el todavía más fascinante personaje desconocido al que nadie conoce y por que el se pregunta el narrador, no para obtener una respuesta, que no la desea pues destruiría justamente el enigma y la atracción de ese retrato de mujer que tanto le seduce, sino con la intención de alimentar el aura de misterio y atracción que lo envuelve. Su álbum es una novela o muchas, más sugerida que contada que termina desbaratándose con el nombre revelado de la mujer del retrato.

"Tus ojos sutiles -escribe- no han podido morir porque los gusanos negros y brillantes que yo conozco, dejan vivo lo que se puede ver al heteroscopio y tus ojos son completamente ojos de heteroscopio ${ }^{13}$ que no dejarán ver el cuenco negro de tu calavera" (Gómez de la Serna, 1996, 1099). Nos recuerda, al paso, los ojos abiertos que el aplicado fotógrafo pintaba a los muertos para devolverles una ilusión de vida, que no de vivir. La imagen, en este caso, significa una forma de supervivencia, de escapar a la devastación del gusano del tiempo.

La anécdota de la bella bañista, que resulta ser una marquesita, a la que un fotógrafo furtivo roba su instantánea 
en la playa de "La fotografía en traje de baño" (El alba y otras cosas, 1923), mandando al traste su matrimonio con el conde Espin, termina en pleito. Conflicto de actualidad que atañe a los derechos de la imagen y el respecto a la intimidad, flagrante en la prensa del corazón, aunque no menos significativo en otras confrontaciones que recorren la relación entre fotógrafos y modelos ocasionales que reclaman sus intereses, al contrario del sueño que Gómez de la Serna relata en una de sus greguerías, donde se imagina convertido en personaje eterno paseándose por una postal o en la imagen de una guía urbana: " hubiera dado cualquier cosa -escribe- por ser uno de esos escogidos" (Gómez de la Serna, 1999, 948).

Las verbenas, otro de los puntos a los que confluyen las historias de Gómez de la Serna, como las escenas de Gutiérrez Solana y Maruja Mallo, o el film Esencia de verbena rodado en 1930 por Ernesto Giménez Caballero, y donde aparece el mismo Gómez de la Serna como muñeco de pim-pam-pum. "Los retratos grotescos de las verbenas", en Toda la historia de la Puerta del Sol y otras muchas cosas (1925), son ontológicos, ofreciendo a intelectuales y artistas la fortuna de dejar de serlo y convertirse para la eternidad en Charlot, torero o chulapona, a Dalí montar en globo, Buñuel dejarse conducir en aeroplano por Lorca. "¿Pero cómo íbamos a perder la ocasión de tener el retrato jovial con que descomponer para siempre todo nuestro prestigio posible?" (Gómez de la Serna, 1999, 1084), concluye satisfecho el autor. Cualquiera de esos retratos es preferible al retrato de boda, concluye. Antes de seguir adelante, señalar que el texto de Ernesto Giménez Caballero "Fotograma"14 perteneciente a Yo, inspector de alcantarillas (1928), aparentemente enigmático, responde ni más ni menos, como su mismo título indica, a la descripción de un fotograma.

Sus Greguerias están jalonadas por sucesivas y permanentes alusiones a la fotografía. Muchas de ellas enigmáticas y de una imaginería surrealizante poderosa ("Cuando los astrónomos fotografian la luna descubren sus pezones de perra muerta"), pretexto en otras para ilustrar una misoginia manifiesta o dar la vuelta al gesto fotográfico: son los gatos o la guitarra los que fotografían a los fotógrafos, 0 los marineros que sirven de modelo los que contagian sus rayas de marinero a cuantos posan en el paseo. Algunas son de carácter futurista, como la del auto con la cámara en el parachoques para fotografiar atropellos, a la vez que se preocupan de la mirada en los retratos y reinventan objetos al modo surrealista de los objets trouvés: "Las máquinas registradoras nos hacen la instantánea del precio", o bien las máquinas fotográficas se convierten en acordeones 0 en viudas locas, y los fotógrafos en toreros colocándose para entrar a matar, o esa maravillosa definición esencial de una "Instantánea: dos senos con jersey".

La greguería "Hay que dejar que las imágenes se acerquen a nosotros. Nosotros nos podemos acercar a las cosas, pero no a las imágenes" señala uno de los aspectos fundamentales que atañen a la realidad representada. Sobre este diálogo entre verdad y representación tratan un número significativo de ellas, desde el síndrome Dorian Grey o los temores que ya Balzac confiesa a Nadar sobre las capas superpuestas de espectros que perdemos con cada retrato, hasta concluir en la condena a muchos años de prisión para el fotógrafo que se dedicaba a captar almas incautas en el parque (Caprichos, 1925).

Lo cierto es que retratistas y retratados, aunque no la fotografía, salen malparados a manos de Gómez de la Serna. Personajes inciertos, patosos y burdos, infernales incluso, que viven con su pecado original a cuestas ("Si hubiese habido fotógrafo en el Paraiso, habría sido bochornoso el retrato de bodas de Adán y Eva") son confinados a la torpeza ("El fotógrafo de jardín tiene tan mala puntería, que se ofrece a fotografiar al que va a suicidarse"), al ridículo ("Los verdaderos marcianos son los fotógrafos de jardín cuando aparecen entre los árboles con su aparato a cuestas") y al agravio ("Cuando entra la gran belleza en la fotografía se desmaya el fotógrafo"). Siempre queda la extraña belleza de esa mujer que acaba de lavarse la cabeza. Las opiniones de Gómez de la Serna sobre la fotografia, que casi podrian resumirse a comentarios sobre el género del retrato, se vuelven más amables en el capítulo que le dedica en su Automoribundia (1948). Alli hace un repaso de los aspectos más importantes que conciernen a esta práctica fotográfica: la imagen como idealización, su parte fetichista, el reducto de salvación frente al paso de tiempo, los primeros retratos de estudio con luz natural y el humilde retrato callejero, la fotografía como "archivo general de la vida". Gómez de la Serna añade poco después un adjetivo que matiza y precisa uno de los aspectos que mejor definen el universo de la imagen fotográfica: "la vida modesta". La fotografía como archivo general de la calderilla de la vida. 
El amasijo de trastos que se amontonan en el rastro de Ramón Gómez de la Serna resulta ser el mismo amasijo que el detallado por José Gutiérrez Solana cuando describe la plaza mayor de Segovia de su España negra (1920), solo que los objetos de Gómez de la Serna se convierten ahora en un retablo de personajes de carne y hueso. En esa plaza esperan los fotógrafos de portal, los de jardín, tan vilipendiados en Gómez de la Serna, y el censo de los retratados que posan en sus escaparates no tiene desperdicio.

"Peregrino sentado" (1924) de Juan Chabás perpetua la tradición de los grandes viajeros que nunca abandonan su sillón de orejas junto a la chimenea del salón, desde donde han recorrido el mundo a través de postales y álbumes de viajes. El protagonista del relato de Chabás, a la manera de Xavier de Maîstre alrededor de su dormitorio y el conde Des Esseintes en los viajes artificiales de su retiro en Fontenay-aux-Roses, recorre el mundo con la imaginación sin salir de su casa ayudado por mapas descoloridos, libros y fotografías, viajando a su niñez "entornando los ojos, como si quisiera enfocarla en la media luz de su cuarto". Henry James anunció el final de los viajes en The Aspern Papers (1888) porque la fotografía eliminaba toda sorpresa. Lo cierto es que con la fotografía se inaugura el período de las expediciones fotográficas, que acercaban el mundo lejanísimo y hostil a la comodidad sedentaria del "peregrino sentado".

Está en lo cierto Ana Rodríguez-Fisher cuando, en la presentación que hace en Prosa española de vanguardia del relato de Gerardo Diego "Cuadrante (Noveloide)" (1926), afirma que los rasgos visuales del texto rinden tributo a la estética cubista más que a un origen cinematográfico. La clave, no obstante, es fotográfica, tanto por la alusiones específicas al medio como por los fragmentos que describen precisas composiciones geométricas estrechamente vinculadas al empleo de la iluminación, propias de un director de fotografía: "Centro o, por mejor decir, foco lateral como en la elipse". Basta con reparar en las numerosas indicaciones a fuentes de luz y efectos de sombras que reúnen objetos y personajes en figuras deliberadamente compuestas desde un punto de vista fotográfico.

El alfil Agudo, por otra parte, es percibido "de medio perfil, en ángulo de $45^{\circ}$, actitud favorita para el fotógrafo". Las referencias a prismas y formas geométricas que adoptan unos pantalones, la figura de Agudo que "se agigantaba, se abstractizaba en una poderosa, imperiosa alucinación geométrica" recuerdan los retratos vortográficos de Alvin Langdon Coburn, próximos a la estética cubista. El personaje Impaciente ve a Agudo "desenfocado" y los rombos del tablero de ajedrez se alargan volviéndolos afilados, romboidales en "una visión como la que a veces obtienen las cámaras fotográficas". Las evocaciones del propio lenguaje en términos como "fotosfera", la preferencia del rectángulo, formato del paso universal en fotografía, al cuadrado o al círculo, y el "pavoroso destino" al que siente abocado Agudo "como si nos debiéramos contra un inmenso espejo sin salida, porque nuestros enemigos son inversos, esto es, son iguales" se impone como metáfora precisa del cuadrante fotográfico, del espejo sin salida que es el retrato, enemigo, inverso e igual, y a donde cae por el ojo de la cámara el futuro de sus protagonistas.

A lo largo de los capitulos que forman La llama (1946), última entrega de la extraordinaria y emotiva novela de Arturo Barea La forja de un rebelde, se sucede un episodio en donde unas fotografías de niños víctimas de un bombardeo traen a reflexión el aspecto no sólo gráfico de la fotografía, sino de responsabilidad y compromiso ideológico implícito en las imágenes. La puesta a salvo de esas imágenes ${ }^{15}$, donde a fin de cuentas se trata de poner a salvo y al servicio de la memoria, lleva implícito un peligro y una decisión moral, por parte del que realiza las fotos y del que decide, como el narrador de La forja de un rebelde, recuperar esas imágenes terribles que más tarde verá convertidas en vallas publicitarias denunciando el horror y la muerte ${ }^{16}$.

El uruguayo Enrique Amorim subraya en el relato "La fotografía", incluido en el libro Después del temporal (1953), la ficción que encierra toda imagen ${ }^{17}$. En su relato, Amorim detalla la historia de Madame Dupont, que acude al estudio del fotógrafo para hacerse un retrato donde poder escribir la dedicatoria "A mi inolvidable madre querida, en el patio de mi casa con mi mejor amiga". La puesta es escena del patio y de la amiga tienen lugar en el mismo estudio fotográfico. El cuento de Amorim aborda uno de los asuntos más importantes vinculados a la fotografía, tanto desde un punto de vista cotidiano como en su dimensión artística: la imagen como invención.

La imagen como trasgresión es la base argumental que sirve a Juan Carlos Onetti para imaginar en su cuento "El 
infierno tan temido" (1957) la historia de una mujer que, para vengarse de su marido, no se le ocurre otra cosa mejor que enviarle autorretratos obscenos, primero a él y luego a todo Santa Maria, con el propósito de someter a humillación ${ }^{18}$ más allá de lo estrictamente moral dando forma, haciendo visible el desamor, el rencor mediante la herida de cada una de las instantáneas que Gracia César envía a Risso.

Silvina Ocampo recurre a la fotografía para organizar uno de los relatos que componen La furia (1959). "Las fotografias" son ocho instantáneas realizadas durante el cumpleaños de su protagonista, a quien se pretende agasajar con una fiesta en una doble celebración: su cumpleaños ${ }^{19}$ y la salida del hospital tras un grave accidente. Cada una de las instantáneas es descrita con todo detalle y sirve como excusa para introducir a los invitados a la fiesta. La fotografia familiar desempeña un papel decisivo y estimulante, tanto en el imaginario colectivo como en su influencia directa en la articulación de la estética literaria moderna, tanto en los temas, como sucede en el caso de Silvina Ocampo, como en la forma, situándose en el origen de la fragmentación del discurso narrativo en parcelas temporales.

El relato de Cesar González-Ruano "La carta", de su libro A Todo el mundo no le gusta el amarillo (1961), ambientado en Sicilia, aunque bastaría con cambiar los nombres de Carlino por el de Carlos para transplantar la trama a la España del boom turistico de los años sesenta, hace referencia a dos aspectos significativos de la fotografía como son lo pintoresco y el fetiche. Carlino odia el turismo y las turistas que le han permitido vivir y hasta enriquecerse. Ellas se llevan de vuelta a casa su colección de conchitas, aventuras amorosas y "fotografías estúpidas". Su pueblo le aburre hoy "igual que una insoportable fotografía". Viejo y enamorado escribe una carta imposible a la mujer deseada en secreto para declararle todo su amor y todo su odio juntos.

Se trae de Salerno un fotógrafo "para poseer clandestinamente una fotografía suya en traje de baño" (González Ruano, 1965, 188), de la que tiene que hacer varias copias sucesivas porque las rompe en momentos de desesperación amorosa sirviéndose de la imagen como fetiche que recibe tanto sus besos como su rencor. El uso fetichista de la fotografía cuenta con ilustres adictos. Entre los más conocidos está Marcel Proust con esa escena en Du côté de chez Swann donde Mademoiselle Vinteuil recurre al retrato de su padre para hacerle presenciar sus juegos amorosas lésbicos y despreciarlo a través de la fotografía.

La condición de periodista de González-Ruano refleja una especial atención hacia el trabajo fotográfico, como lo prueba su deseo expreso de hacer constar la autoría de J. M. Pastor para los retratos que acompañan e ilustran sus entrevistas en Las Palabras quedan (conversaciones) (1957), del mismo modo que la portada de Nuevos descubrimientos del mediterráneo (1959) pertenece a KINDEL (Joaquín del Palacio). En algunas de sus trescientas prosas, recogidas en La vida íntima (1995), las imágenes cobran una especial relevancia entretejiendo fotografía, tiempo y enfermedad en un sugerente hilván.

En 1967 Ramón J. Sender agrupaba unos relatos bajo el título La llave y otras narraciones. El titulado "La fotografía de aniversario" cuenta la historia de un fotógrafo de estudio y su señora el día de su aniversario de bodas ${ }^{20}$. En el cuento de Sender la acción se desarrolla en mismo estudio fotográfico, y los diferentes retratos que cuelgan de las paredes están al servicio de un misterio nunca revelado creando la tensión del relato en torno a entredichos, suposiciones y silencios, cargados de una gran ironía. Ramón J. Sender aborda el personaje del fotógrafo con un gran sentido del humor, haciendo hincapié en la manipulación de las luces y las poses de sus modelos con una intención que va más allá del retrato.

Si el cuento de Cesar González-Ruano hablaba del turismo, "La fotografia" de Carmen Laforet pone en solfa el reverso de una España de turistas churruscados que aspiraba a nación "en vías de desarrollo" y encontraba en sus emigrantes una forma de supervivencia. El tiempo contado por Carmen Laforet es el tiempo de aquellos que cuando necesitaban un retrato acudían al fotógrafo del barrio repeinados, y entonces tiraba de la barbilla hasta dar con el ángulo perfecto desde donde mirar de reojo la pobreza con su olor a fritanga, calcetines húmedos y sardina rancia. El retrato que Leonor quiere de su niño para Sebastián es un retrato deseado, construido, al igual que el descrito por Gómez de la Serna en su Automoribundia o el de Madame Dupont en el relato de Enrique Amorim.

Son numerosos y diversos los relatos y novelas que rinden en sus páginas un tributo a la fotografía. Para concluir 
aquí van algunos títulos recientes que dan testimonio de la deuda permanente que la literatura ha contraido con las imágenes fotográficas desde que en 1839 François Arago diera a conocer el invento de Daguerre que habría de cambiar la manera de ver y verse en el mundo. En las novelas La foto de los suecos (1998) de Juan Cruz, El veneno de la fatiga (1999) de Javier Herrezuelo y La ruta de Esnábel (2001) de Vital Citores, la fotografía ocupa un lugar determinante en la articulación argumental de las tres novelas. Fernando Vallejo imagina en La rambla paralela (2002) una fantasía visual que consiste en la aceleración del tiempo por acumulación de retratos de un mismo individuo con el objeto de constatar el paso de los años en los cuerpos y rostros, tal y como los fotógrafos Nicholas Nixon y Pere Formiguera lo ha llevado a cabo en sus trabajos Las hermanas Brown (1975-2007) y Cronos (1991-2001) respectivamente, y es que "se envejece más y peor en los retratos que en la realidad" pone García Márquez en boca del narrador de Memorias de mis putas tristes (2004). En el relato "bar de anarquistas" (2005) de José María Conget, que da título al libro, una polaroid ocasional realizada por una turista americana a sus protagonistas ocupa el centro neurálgico de la historia, así como las fotografías del álbum familiar descritas por el narrador de Nuestra epopeya (2006) de Manuel Longares o las que Sacramento Andreini contempla en la soledad de su salón hasta el día de su muerte en uno de los cuentos de Julián Ríos que componen Cortejo de sombras (2007). Rafael Chirbes en Crematorio (2007) subraya la importancia de los personajes anónimos que aparecen en las fotos y nosotros como personajes desconocidos en las fotos ajenas.

Buena parte de los aspectos que caracterizan la forma y el fondo de la narrativa moderna, entendiendo que la modernidad literaria empieza en el último cuarto del siglo XIX con la reacción de la estética simbolista y decadente en Francia ante la hegemonía del realismo, no pueden ser explicados sin tener en cuenta las mutaciones que la fotografía introdujo en el mundo del arte y de la literatura. Los antihéroes, el monólogo, la narración subjetiva y en presente, el nacimiento del poema en prosa como género literario, la vida cotidiana y anónima como argumento, la fragmentación del texto son aspectos, entre otros muchos, que han de entenderse desde una perspectiva fotográfica. De otro modo, estaríamos pasando por alto uno de los fenómenos comunicativos más influyentes y decisivos de nuestro tiempo.

\section{NOTAS}

1 Ver bibliografía específica al final del trabajo.

2 Ya en 1867 Joan Cortada calificaba su colección de relatos $L a$ voz de la conciencia como "fotografías escritas" y el doctor Pedro Mata, introductor de la medicina legal en España, novelista y poeta, reunió sus versos (románticos) completos en un volumen curiosamente titulado Fotografías íntimas, de 1875

3 Agustín Sánchez Vidal volverá a utilizar este mismo argumento en Llave maestra.

Recibido: 15 de octubre de 2008

Aceptado: 14 de mayo de 2009
4 Unamuno se hace eco de los trabajos de Arthur Batuty su obra L'Application de la photographie à la production du type d'une famille, d'une tribu, d'une race (1887), de donde toma casi al pie de la letra la descripción que Batut hace de su procedimiento. El fotógrafo Bathut pretendía, desde una perspectiva científica, conseguir extraer y aislar mediante la sobreimpresión los estereotipos faciales de una familia o grupo. Estas investigaciones fotográficas quedan enmarcadas en el contexto que a finales de siglo XIX corresponden también a los trabajos del italiano Lombroso en 1870 primero, y de Alphonse Bertillon en Francia en 1882 al servicio de la investigación policial con el objetivo de establecer una tipología que permitiera describir e identificar unos rasgos físicos propios de los criminales. 
5 Una costumbre, por otra parte, muy extendida en las ciudades portuarias de América a principios del siglo XX.

6 Desde Poe a Henry James, Walter de la Mare o Villiers de I'Isle Adam, lo sobrenatural se hace protagonista indiscutible de cuentos y relatos. No sólo la literatura aborda el tema de los fantasmas desde el punto de vista de la ficción. Médicos como el propio Baroja, Hippolyte Baraduc o Enrico Imoda en L'Ame humaine, ses mouvements, ses lumières et l'iconographie de l'invisible fluidique (1896) y Fotografie di fastasmi (1912), así como el escritor Arthur Conan Doyle, defienden y The Wanderings of a Spiritualist (1922), la existencia de una realidad extracorporal que se sustrae a la visión de las personas y que el aparato fotográfico es capaz de captar. Existen no pocos ejemplos que recogen estos intentos por captar la presencia del más allá a través del objetivo de la cámara. El propio Conan Doyle trató de probarlo mediante fotografías.

7 El caso más célebre y repetido es el del cuento de Julio Cortázar "Las babas del diablo", incluido en Las armas secretas (1959), y que inspirará igualmente el no menos célebre y aplaudido film de Antonioni Blow Up (1966). Al revelar unas fotografias en el laboratorio que ha realizado a una pareja y un tercer personaje masculino enigmático, el personaje Roberto comprueba, en el cuento de Cortázar, que la realidad de la fotografía altera la realidad que como fotógrafo y testigo creía haber presenciado. Sus fotos han visto otra realidad distinta a la que sus ojos creyeron ver.

8 Désiré François Millet fue uno de sus máximos representantes. Ver también (2007) Post Mortem, Paris, Centre National de la Photographie, Colección PhotoPoche.
9 Ver su libro más representativo García Rodero, Cristina (1989): La España oculta, Madrid, Lunwerg.

10 Incluidos también en Una estrella roja.

11 Son numerosos los libros y las exposiciones que han sido dedicadas a Robert Capa.

12 Consultar el reciente trabajo de Olmeda, Fernando (2007): Gerda Taro, fotógrafa de guerra, Madrid, Debate.

13 Gómez de la Serna hace alusión a la práctica fotográfica que, mediante una cámara con dos objetivos, se obtenía un doble negativo, revelado en cristal y visionado en tres dimensiones mediante un estereóscopo. El término "heteroscopio" utilizado por Gómez de la Serna responde probablemente a un error, queriendo decir estereoscopio. Para ser exactos, estereóscopo es el nombre del aparato inventado por el físico inglés Charles Wheatstone y presentado en Londres en 1838 con el que conseguir una visión en relieve.

14 El fotograma consiste en un procedimiento que se sitúa en el origen mismo de la fotografía. Talbot comienza a experimentar con sus photogenic drawings en 1839 y de la misma época datan los trabajos de Bayard con hojas, plumas y telas. La técnica del fotograma consiste en disponer objetos directamente sobre el soporte sensible que, una vez expuestos a la luz y revelados, se recortan en claro sobre el fondo oscuro del papel. En la historia del medio los fotogramas han quedado vinculados a las vanguardias históricas, aunque el primer reconocimiento de una dimensión estética corresponde a los realizados por Christian Schad en 1918. Durante el período de entreguerras, tienen lugar los trabajos de Moholy-Nagy para la Bauhaus y Man Ray con su Champs délicieux, acompañado de un texto de Tzara.
15 Escenas similares han tenido lugar en otros conflictos y situaciones extremas, como los negativos escamoteados a los SS de Mathaussen por Francesc Boix (2002): Francesc Boix, el fotograf de Mauthausen (Benito Bermejo Sánchez ed.), Barcelona, La Magrana.

16 La descripción que Barea hace de esas fotografias y de ese cartel se corresponde con el publicado por el Ministerio de Propaganda y expuesto, en versión inglesa, en la exposición de 2002 The Spanish Civil War. Dreams + Nightmares organizada por el Imperial War Museum de Londres.

17 Cuenta Richard Avedon cómo su madre posaba ante la casa de los vecinos y tomaban prestado su perro para componer la imagen de una familia tan ideal como irreal. La puesta en escena como disciplina se ha convertido en el terreno creativo en todo un género, del que Joan Fontcuberta es uno de sus máximos representantes. Otros fotógrafos como Claude Cahun, Pierre Molinier o Sophie Calle han recurrido el autorretrato como medio de explorar la identidad.

18 La imagen aquí hunde sus raices en lo más profundo de sus orígenes fetichistas que Hans Belting estudia en (2004), Pour une anthropologie des images, Paris, Gallimard (Col. Le Temps des images).

19 En el ya clásico Bourdieu, Pierre (1965): Un art moyen. Essai sur les usages sociaux de la photographie, Bourdieu dejaba claro que la práctica doméstica fotográfica quedaba limitada a una serie de circustancias limitadas como las celebraciones familiares. Lo que en el ensayo de Bourdieu quedaba circunscrito a un espacio con más límites que creatividad, otros trabajos posteriores, como el de Bertrand Mary (1993): La photo sur la cheminée. Naissance d'un culte moderne, Paris, Métailié; Garat, 
Anne-Marie Garat (1994), Photos de familles, Seuil, o Hirsch, Marianna (1997), Family Frames. Photography, Narrative and Postmemory, Harvard University Press, abiertos más allá de los sociológico.

20 El fotógrafo pertenece a lo que popularmente se conoce, sin cierta condescendencia, como los de la BBC (Bodas, Bautizos y Comuniones). Trabajos como los de Juan de la Cruz Megías demuestran que la fotografía de bodas no sólo pueden alcanzar por méritos propios el calificativo de obra de arte, sino que en el caso de Megías está muy por encima de algunas pretensiones supuestamente artísticas. Consultar de Juan de la Cruz Megías sus libros (1999) Bodas/ Weddings, Barcelona, H2O (2005) Vivan los novios, La Fábrica, y (2007) Pan, vino y azúcar, Zaragoza, PUZ.

\section{BIBLIOGRAFÍA}

\section{Fuentes}

Barea, Arturo (2000): La forja de un rebelde (Introducción de Nigel Townson), Madrid, Debate.

Baroja, Pío (1998): Vidas sombrías (Introducción por José-Carlos Mainer), Madrid, Biblioteca Nueva.

Bioy Casares, Adolfo (1972): La Invención de Morel, Madrid, Alianza.

Citores, Vital (2001): La ruta de Snábel, Madrid, Espasa Calpe.

Conget, José María (2005): Bar de Anarquistas, Valencia, Pre-Textos.

Cruz, Juan (1998): La Foto de los suecos, Madrid, Espasa, 1998.

Chirbes, Rafael (2007): Crematorio, BarceIona, Anagrama.

García Márquez, Gabriel (2004): Memorias de mis putas tristes, Barcelona, Mondadori.
Giménez Caballero, Ernesto (1975): Yo, inspector de alcantarillas, Madrid, Turner, 1975.

Gómez de la Serna, Ramón (1955): Total de greguerías, Madrid, Aguilar

Gómez de la Serna, Ramón (1962): Caprichos, Madrid, Espasa Calpe.

Gómez de la Serna, Ramón (1972): Automoribundia, Madrid, Guadarrama.

Gómez de la Serna, Ramón (1982): Greguerías (edición de Rodolfo Cardona), Madrid, Cátedra.

Gómez de la Serna, Ramón (1996): Obras completas I. "Prometeo" I. Escritos de juventud (1905-1913) (Edición dirigida por loana Zlotescu. Revisión de los textos por Juan Pedro Gabino. Coordinación documental de Pura Fernández. Con el asesoramiento de José-Carlos Mainer. Prólogos de José-Carlos Mainer y loana Zlotescu), Barcelona, Círculo de Lectores/Galaxia Gutenberg.

Gómez de la Serna, Ramón (1998): Obras completas III. Ramonismo I. El rastro. El circo. Senos (1914-1917) (Edición dirigida por loana Zlotescu. Revisión de los textos por Juan Pedro Gabino. Coordinación documental de Pura Fernández. Con el asesoramiento de José-Carlos Mainer. Prólogo de César Nicolás), Barcelona, Círculo de Lectores/Galaxia Gutenberg.

Gómez de la Serna, Ramón (1997) Obras completas IV. Ramonismo II. Greguerías. Muestrario (1917-1919) (Edición dirigida por loana Zlotescu. Revisión de los textos por Juan Pedro Gabino. Coordinación documental de Pura Fernández. Con el asesoramiento de José-Carlos Mainer. Prólogo de José Enrique Serrano), Barcelona, Círculo de Lectores/Galaxia Gutenberg.

Gómez de la Serna, Ramón (1999): Obras completas V. Ramonismo III. Libro nuevo. Disparates. Variaciones. El alba (1920-1923) (Edición dirigida por lo- ana Zlotescu. Revisión de los textos por Juan Pedro Gabino. Coordinación documental de Pura Fernández. Con el asesoramiento de José-Carlos Mainer. Prólogo de Rafael Conte), Barcelona, Círculo de Lectores/Galaxia Gutenberg.

González Ruano, César (1957): Palabras quedan (conversaciones), Madrid, Afrodisio Aguado.

González Ruano, César (1959): Nuevos descubrimientos del mediterráneo, Madrid, Afrodisio Aguado.

González Ruano, César (1961): A todo el mundo no le gusta el amarillo, Madrid, Afrodisio Aguado.

González Ruano, César (1995): La Vida intima, Madrid, Fundación Cultural MAPFRE VIDA.

Gutiérrez Solana, José (1998): La España negra, Granada, La Veleta.

Herrezuelo, Javier (2000): El veneno de la fatiga, Madrid, Alianza (Col. Alianza literaria).

Laforet, Carmen (1957): Obras completas, Vol. 1, Barcelona, Planeta.

León, María Teresa (1975): Memoria de la melancolía, Barcelona, Bruguera.

León, María Teresa (1979): Una estrella roja, Madrid, Selecciones Austral. Espasa-Calpe.

León, María Teresa (1987): Juego limpio, Barcelona, Seix Barral.

Longares, Manuel (2006): Nuestra epopeya, Madrid, Alfaguara.

Oviedo, José Miguel (ed.) (1992): Antología de cuento hispanoamericano del siglo XX (1920-1980) (1. er volumen) (Selección de José Miguel Oviedo), Madrid, Alianza.

Pérez Galdós, Benito (1980): La vuelta al mundo en la "Numancia", Madrid, Alianza.

Quiroga, Horacio (1995): Más cuentos (Introducción de Arturo Souto Alabarce), Mexico, Editorial Porrúa (Col. Sepan cuantos, n. ${ }^{\circ}$ 347). 
Ríos, Julián (2008): Cortejo de sombras, Barcelona, Galaxia Gutemberg/Círculo de lectores.

Rodríguez-Fischer, Ana (1999): Antología de la prosa española de vanguardia Madrid, Castalia.

Sánchez Vidal, Agustín (2005): Llave maestra, Madrid, Santillana.

Sender, Ramón J. (1967): La llave y otras narraciones, Madrid, Magisterio Español.

Unamuno, Miguel de (1991): En torno al casticismo, Madrid, Espasa Calpe, Colección Austral (Introducción de Luciano González Egido).

Vallejo, Fernando (2002): La Rambla paralela, Barcelona, Alfaguara.

W.AA. (1970): 70 años de narrativa argentina 1900/1970, Madrid, Alianza.

\section{Bibliografía específica}

Ansón, Antonio (2007): El limpiabotas de Daguerre, Murcia, Puertas de CastiIla.

Ansón, Antonio (2000): Novelas como álbumes. Fotografía y literatura, Murcia, Mestizo.

Ansón, Antonio (1992): El istmo de las luces. Poesía e imagen de la vanguardia, Madrid, Cátedra.

Ansón, Antonio (ed.) (2002): "Foto \&t poesia", Riff Raff, n. 19, Zaragoza, ediciones Mira.

Ansón, Antonio (ed.) (2003): Los mil relatos de la imagen y uno mas, Huesca, DPH, 2003.

Ansón, Antonio y Scianna, Ferdinando (eds.) (2009): Las palabras y las fotos. Literatura y fotografía, Madrid, Ministerio de Cultura.

Arrouye, Jean (dir.) (2005): La photographie au pied de la lettre, Aix-en-Provence, Publications de I'Université de Provence.

Bann, Stephen y Hermange, Emmanuel (éd.) (2000): Photography and Lite- rature: an Anglo-French symposium, Journal of European Studies, Alpha Academic, vol. 30, part. I, n. 117.

Brassai (1997): Marcel Proust sous l'emprise de la photographie (Préface de Roger Grenier), Paris, Gallimard.

Brunet, François (2009): Photography and Literature, London, Reaction Books.

Bryant, Marsha (ed.) (1996): Photo-Textualities: Reading Photographs and Literature, Newark, University of Delaware.

Buisine, Alain y Watteau, Emmanuel (eds.) (1995): Photographie-littérature, Mannheim, Medusa-Médias, 2, Universidad de Mannheim.

Cadava, Eduardo (1997): Words of Light. Theses on the Photography of History, New Jersey, Princeton University Press.

Caraion, Marta (2003): Pour fixer la trace. Photographie, littérature et voyage au milieu du XIX siècle, Genève, Droz.

Chevrier, Jean-François (1982): Proust et la photographie, Paris, Editions de I'Etoile.

De Romanis, Roberto (ed.) (1996): L'Asino d'oro ("Fotografia e letteratura"), n. 9.

Hapkemeyer, Andreas y Weiermair, Peter (eds.) (1996): Photo text text photo: the synthesis of photography and text in contemporary art, Zurich, Edition Stemmle.

Hunter, Jefferson (1987): Images and Word: The Interaction of Twentieth-Century Photographs and Texts, Cambridge, Harvard Univesity Press.

Infantino, Stephen C. (1992): Photographic Vision in Proust, New York, Peter Lang.

Jaguer, Edouard (1982): Les Mystères de la chambre noire. Le surréalisme et la photographie, Paris, Flammarion.

Koppen, Erwin (1987): Literatur und Photographie; Über Geschichte und Thematik Einer Medienentdeckung, Stuttgart, J.B. Metzler.
Lambrechets, Eric y Salu, Luc (1992): Photography and Literature. An Interntional Bibliography of Monographs, London, Mansell.

Méaux, Daniel (ed.) (2006): Etudes romanesques 10: "Photographie et romanesque", Caen, Lettres Modernes Minard.

Montier, Jean-Pierre; Louvel, Liliane; Méaux, Danièle y Ortel, Philippe (dirs.) (2008): Littérature et photographie (colloque au Centre International de Cerisy-la-Salle), Presses Universitaires de Rennes (coll. Interférences).

Mormorio, Diego (ed.) (1988): Gli Scrittori e la fotografia (pref. de Leonardo Sciascia), Roma, Editori Riuniti/Albatros (XXVIII).

Morris, Wright (1989): Time Pieces. Photographs, Writing, and Memory, New York, Aperture.

Ortel, Philippe (2002): La littérature à l'ère de la photographie. Enquête sur une révolution invisible, Nîmes, Editions Jacqueline Chambon (Coll. Rayon Photo).

Rabb, J. M. (ed.) (1995): Literature and Photography. Interactions, 1840-1990. A Critical Anthology, Alburquerque, University of New Mexico Press.

Shloss, Carol (1987): In Visible Light. Photography and the American Writer 1840-1940, New York, Oxford University Press.

York, Lorraine Mary (1988): Photography in the Works of Alice Munro, Timothy Findlay, Michael Ondaatje, and Margeret Laurence, Toronto, ECW Press.

W.AA. (1997): ExtraCAMARA, n. 9 ("Fotografía \& Literatura"), Caracas-Venezuela, Consejo Nacional de la Cultura.

W.AA. (1981): Les Cahiers de la photographie, n. 2 ("Littérature/Photographie").

W.AA. (1992): Les Cahiers Naturalistes, n. 66, Actes du Colloque de la Bibliothèque Nationale, Paris/Médan: 4-7 octobre 1990 (Tercera parte: "Naturalisme et photographie"). 